\title{
Драйверы \\ и барьеры сельской реиндустриализации *
}

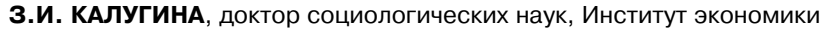
и организации промышленного производства СО РАН, Новосибирский государственный университет. E-mail: zima@ieie.nsc.ru

В.И. НЕФЁДКИН, кандидат экономических наук, Институт экономики и организации промышленного производства СО РАН, Новосибирск.

E-mail: vladnn57@gmail.com

О.П. ФАДЕЕВА, кандидат социологических наук, Институт экономики и организации промышленного производства СО РАН, Новосибирский государственный университет, Новосибирск. E-mail: fadeeva_ol@mail.ru

Статья подготовлена по итогам краткосрочной научной экспедиции в Маслянинский район Новосибирской области. Ее целью было продолжение мониторинга социально-экономических процессов, происходящих в современной российской деревне, изучение природы «маслянинского чуда», наблюдение осязаемых сдвигов в экономике района и примечательных черт сельского образа жизни. Ключевые слова: сельское развитие, реиндустриализация, государственно-частное партнерство, территория опережающего развития, Маслянинский район

В 2013 г. в журнале «ЭКО» было опубликовано интервью с главой Маслянинского района Новосибирской области В.В.Ярмановым под названием «Рецепты “маслянинского чуда"» [1]. За шесть лет реализации долгосрочной программы развития района из «периферийной территории» он превратился в одного из лидеров области в производстве молока, вышел на передовые позиции в льноводстве в общероссийских масштабах, стал популярным центром зимнего отдыха горожан. Предполагались реализация крупных проектов в производстве строительных материалов, дальнейшее увеличение объемов продукции сельского хозяйства с созданием собственной перерабатывающей базы и амбициозный инвестиционный проект в сфере туризма и рекреации.

За прошедшие с момента публикации три года глава района успел поработать в областной администрации и вернулся в район с новыми, еще более грандиозными проектами. В конце сентября 2016 г. мы в очередной раз побывали в районе, события

\footnotetext{
* Статья подготовлена при поддержке РГНФ (проект № 14-03-00332).
} 
в котором нами регулярно отслеживаются в течение последних 15 лет, чтобы разобраться, в какой степени были реализованы старые планы и появились ли новые.

\section{Реиндустриализация \\ в отдельно взятом сельском районе}

Еще задолго до того, как был озвучен замысел Программы реиндустриализации экономики Новосибирской области [2, 3], сходные идеи не только обсуждались, но и начали воплощаться в далеко не самом благополучном по тем временам сельском районе. В середине 2000-х гг. Маслянинский район попал в фокус общественного внимания благодаря нестандартным подходам к разработке стратегии развития сельских территорий и практическим шагам по претворению ее в жизнь. Администрация района поставила задачу выделить и поддержать несколько перспективных проектов, которые бы смогли придать импульс местной экономике, заинтересовать потенциальных инвесторов, создать основания для получения государственной поддержки. Периодические «мозговые штурмы» с привлечением внешних экспертов в конечном счете послужили основой для формирования своеобразного районного центра инновационных и инвестиционных компетенций, а главным результатом работы стала «Комплексная программа социально-экономического развития Маслянинского района на период 2008-2022 гг.», утвержденная в 2007 г. местным советом депутатов [4].

Нет нужды доказывать, что без финансовых ресурсов и организационной поддержки большинство такого рода программ обречены на провал. Однако в Маслянинском районе ситуация выглядела иначе. С энтузиазмом, не меньшим, чем в момент составления планов, последние принимались к исполнению. Одной из сложнейших проблем в практической реализации крупных проектов является совместное использование государственных и частных денег, а государственно-частное партнерство пока слабо подкреплено законодательно защищенными и реально работающими механизмами. Совмещение частного и государственного финансирования в рамках одного проекта в современных российских условиях крайне рискованно, а его результаты могут интерпретироваться в широком диапазоне от «разумной 
инициативы на местах» до «нецелевого использования средств» со всеми вытекающими последствиями для участников.

Администрация Маслянинского района Новосибирской области нашла свой способ решения означенной проблемы. На вооружение был взят принцип «предпродажной подготовки», который позволил предлагать не идеи для будущих инвестиций, а предварительно «упакованные» бизнес-проекты в виде работающих юридических лиц. Для этого под каждый проект создавались муниципальные унитарные предприятия (МУП). Одно из них возникло на базе нескольких обанкротившихся сельскохозяйственных предприятий. Руководство одного из таких сельхозпредприятий активизировало консолидацию земельных долей и формирование земельных участков с их последующим правовым оформлением. Для рекультивации полей, несколько лет простоявших без обработки, была использована сельхозтехника, приобретенная на выделенные из областного бюджета средства.

Другим «бизнес-проектом» стал новый завод по переработке льна, созданный на месте обанкротившегося льнозавода. Усилиями главы района вновь зарегистрированное МУП было включено в специальную федеральную программу по развитию льноводства, в рамках которой около 150 млн руб. были выделены на модернизацию мощностей по переработке льна.

Параллельно районные власти усиленно искали инвесторов, готовых выкупить у района существующий бизнес, развить его и обеспечить в дальнейшем поток дополнительных поступлений в местный бюджет, необходимых для реализации других, в том числе социальных проектов. Администрацию в первую очередь интересовали компании, которые смогли бы соединить в один технологический процесс производство и переработку местного сырья и тем самым максимизировать произведенную в районе добавленную стоимость.

Глава района в беседах с нами неоднократно отмечал преимущества крупных компаний в качестве потенциальных инвесторов для района. Вместе с тем, по его мнению, конкуренция между несколькими крупными производителями защищала бы местную экономику от излишней монополизации, способствовала повышению эффективности использования земли, увеличению числа рабочих мест и налоговых поступлений. В итоге якорным инвестором стал российско-немецкий животноводческий холдинг 
«Эконива», зарегистрировавший в районе дочернюю компанию «Сибирская нива». Льноводческую отрасль возглавила новосибирская корпорация «Хорс», создавшая хозяйство по производству льна и приватизировавшая через процедуру банкротства МУП обновленный льнозавод. Другим значимым проектом, привлекшим внешние инвестиции, стал туристический комплекс «Юрманка», начало развитию которого положило пролоббированное местными властями строительство подъездных дорог.

\section{Государственно-частное партнерство: смена концепции}

Стратегия развития территории на тот момент сводилась к созданию и реализации отдельных бизнес-проектов, под каждый из которых «затачивались» уникальные механизмы государственно-частного партнерства в рамках отраслевых программ по софинансированию инвестиционных затрат. По оценке В.В. Ярманова, такой подход оказался вполне успешным: «За эти годы мы смогли привлечь в Маслянинский район около 10 млрд руб. инвестиций, включая средства на газификацию, строчтельство соииальных объектов». За прошедшее десятилетие качественно изменился облик районного центра.

Маслянино стало одним из первых районных центров Новосибирской области, где появились спортивный комплекс и бассейн, а занятия спортом стали доступны для жителей сельской местности. Школьников из разных сел стали привозить в райцентр для занятий плаванием и другими видами спорта. В районе открылся комплексный социально-оздоровительный центр, куда на отдых по путевкам социальных служб направлялись пенсионеры со всех районов области. Активно развивались жилищное строительство, благоустройство. Из местных материалов в Маслянино и близлежащих селах были построены несколько микрорайонов и отдельных жилых зданий, предназначенных для разных социальных групп (молодежи, ветеранов). Была проведена реконструкция центрального Дома культуры и корпусов районной больницы. В одном из сел появились новая современная школа, а в самом Маслянино - детский сад.

Повышенное внимание к «экстерьеру» не случайно. Глава администрации уверен, что облагораживание пространства, в котором живут люди, меняет их взгляды и культуру, задает 
вектор трансформации образа жизни: «Bbl посмотрите, как из года в год у нас все меняется, становится чище, красивее, у нас люди меняются». Формирующиеся стандарты социального обустройства территории - это сигнал для будущих инвесторов, для которых облик населенных пунктов может стать дополнительным аргументом для прихода на территорию. Проблема лишь в том, что подобное преобразование пространства более наглядно в административном центре района - и менее заметно в других населенных пунктах.

Частично разрыв в развитии центра и периферии в районе научились преодолевать за счет участия в различных федеральных и региональных программах, мониторингом которых активно занимаются и представители местного самоуправления, и администрация социальных учреждений. Большое подспорье с недавних пор стали оказывать гранты на поддержку местных инициатив по благоустройству улиц, созданию локальных музеев и памятных мест, проведению культурных мероприятий.

\section{TOР как новое «окно возможностей»}

Однако, на наш взгляд, прежняя модель государственно-частного партнерства себя изживает. Комплексное решение проблем территорий только через систему поддержки отдельных проектов стало затруднительным. Поэтому руководство Маслянинского района заявило о смене концепции - переходу от поддержки «точечных проектов» к созданию института сельского развития - формированию инфраструктурной среды для привлечения разных групп предпринимателей, т. е. созданию того, что принято называть «благоприятным инвестиционным климатом».

Стало очевидным, что в рамках одного сельского района сложно решать масштабные задачи, особенно с участием крупного бизнеса. Не случайно в апреле 2016 г. была утверждена «дорожная карта» на создание в рамках трех смежных муниципальных районов - Черепановского, Маслянинского, Сузунского - территории опережающего развития (ТОР) на условиях федерального закона № 473-Ф3 «О территориях опережающего социально-экономического развития в Российской Федерации» от 29.12.2014. Закон определяет порядок формирования на отдельных территориях зон предпринимательской активности, для которых вводятся особые правовые и налоговые режимы. 
Он регламентирует порядок возведения за счет бюджетных и внебюджетных источников имущественного комплекса (инфраструктуры) для привлечения резидентов (частных инвесторов) и заключения с ними договоров с перечнем обязательств перед территорией (количество создаваемых рабочих мест, генерируемый денежный и налоговый поток после отмены льгот и преференций и пр.).

Для работы над созданием нового института сельского развития, каковым может стать ТОР, на базе Агентства инвестиционного развития Новосибирской области был сформирован «проектный офис», объединивший представителей профильных министерств и органов местного самоуправления трех названных районов. Отметим, что до 2018 г. ТОР будут в основном формироваться в ранге пилотных проектов в отдельных регионах Дальнего Востока. Подготовка к продвижению проекта ТОР, который бы смог пройти отбор на федеральном уровне, началась в Новосибирской области заранее.

Важной проблемой является удаленность Маслянинского района от железной дороги и федеральных трасс. Ее отчасти решает преодоление в случае создания ТОР административных границ между тремя районами. Решение проблемы было бы возможно, например, за счет размещения единого промышленно-логистического парка в Черепановском районе - на пересечении железнодорожных и автомобильных транспортных коридоров, с возможностью выхода в соседние регионы и близлежащие страны. На территории парка можно было бы наладить переработку добываемого во всех трех районах сырья и производимых полуфабрикатов с последующим вывозом за пределы ТОР.

На наш взгляд, преждевременно говорить о том, что сложилась определенная модель развития сельских территорий с локальными точками роста, притягивающими к себе бизнес и инвестиции. Новые идеи в развитии территорий видятся инициаторам не как готовые к реализации решения, а как серьезный повод заставить вышестоящие власти выделить ресурсы для «повышения градуса» инвестиционного климата на местах. Тем самым обеспечить опережающую подготовку площадок для бизнеса с юридически чистым землеотводом и готовыми коммуникациями для размещения разных групп взаимосвязанных 
производств, которые в будущем могли бы перерасти в полноценные промышленные кластеры.

В качестве одного из знаковых проектов для будущей ТОР в пределах Маслянинского района рассматривается Губернский парк туризма, спорта и отдыха «Салаир-Олимпик», строительство которого планируется вблизи села Березовое в окрестностях горы Скакуша. Впервые проект был представлен на заседании координационного совета по туризму межрегиональной ассоциации «Сибирское соглашение» в Красноярске в 2015 г. [5]. Анонсировалось, что в парке будут построены спортивные (горнолыжный и биатлонный комплексы, трамплины, фристайлцентр) и инфраструктурные объекты: гостиницы, центры питания, сопутствующие аттракционы для досуга.

Государству в рамках государственно-частного партнерства отводится роль заказчика на строительство спортивных сооружений, позволяющих готовить спортсменов по семи олимпийским видам и обеспечить условия для развития детского спорта. Частный бизнес займется организацией всего комплекса услуг для приема до 350 тыс. туристов в год. Размещение парка согласовано с планами по строительству новой автомобильной трассы - восточного обхода г. Новосибирска. Ввод трассы позволит почти вдвое (до 100 км) сократить расстояние до областного центра.

В рамках парка планируется также строительство промышленных объектов, которые могли бы органично вписаться в местный ландшафт, стать элементами экотуризма. Особой изюминкой парка может стать молокоперерабатывающий завод «под стеклом» (т.е. с доступным для посетителей обзором всего технологического процесса), в строительстве которого заинтересована «Сибирская нива». Сегодня почти весь объем производимого холдингом молока ежедневно отправляется на переработку в Кемерово. После запуска завода холдинг сможет с выгодой для себя завершить интеграцию своего бизнеса.

В апреле 2015 г. ОАО «Агентство инвестиционного развития Новосибирской области» оценивало стоимость проекта парка в 4,5 млрд руб. Предполагалось, что он будет реализован к 2020 г. Понятно, что текущая рецессия и ужесточение бюджетных ограничений могут серьезно скорректировать эти планы и свести к минимуму участие государства. Тем не менее процесс подготовки площадки продолжается. К ней уже подведены электричество 
и технологическая дорога, идет прокладка оптоволокна, прошел экспертизу проект по строительству газопровода. Администрация проделала большую работу по оформлению земли, чтобы войти в федеральную программу и завершить все начатые инженерные работы. Есть задумка создания альтернативной Великому Устюгу резиденции сибирского Деда Мороза, прорабатываются другие туристические проекты, которые не потребуют больших финансовых вливаний, но смогут привлечь инвесторов и отдыхающих. Важно отметить, что газ, устойчивая связь и быстрый Интернет, хорошие дороги станут доступны не только для отдыхающих и спортсменов, но, что более важно, - они придут к жителям близлежащих сел.

Еще одним важным элементом подготовки к созданию ТОР стал областной эксперимент по внедрению концессии в сфере ЖКХ, в котором, начиная с 2016 г., участвуют Маслянинский район и г. Обь. Для модернизации системы теплоснабжения этих двух муниципальных образований Новосибирская область получила 330 млн руб. Для замены устаревшего теплового оборудования в Маслянинском районе будет построено 9 новых газовых котельных и 18 км трубопроводов. Реконструкция тепловых сетей продлится с осени 2016 г. до конца летнего периода 2017 г. Затраты поделены следующим образом: 60\% средств выделены из федерального «Фонда содействия реформированию ЖКХ», $20 \%$ - регионального бюджета и еще 20\% должны составить средства самого концессионера, который затем 25 лет будет управлять этим комплексом.

Помимо аграрного, туристического, инженерно-инфраструктурного, социального кластеров, в Маслянинском районе обретает новую жизнь кластер по добыче полезных ископаемых. В селе Егорьевское силами нескольких артелей ведется разработка новых участков местных золотых россыпей. Другой не менее важный ресурс района - это мрамор, который по качеству не уступает венецианскому и отличается широкой цветовой гаммой. Распространены породы вишневых, бело-розовых, пепельно-серых, зеленых тонов с различной текстурой, а также серых и полосчатых окрасок. Добыча мрамора на нескольких участках на территории района была заброшена 10 лет назад. Прежние разработчики нередко действовали варварски, откалывая куски при помощи взрывчатки, что приводило к образованию трещин 
и ухудшению условий для последующей добычи. На сегодняшний день месторождения находятся в нераспределенном фонде, но, по словам представителей районной администрации, уже найден потенциальный инвестор, который планирует открыть производство с привлечением иностранных партнеров [6].

В числе других перспективных и реализуемых сейчас на территории Маслянинского района проектов стоит отметить создание предприятия по выращиванию и переработке грибавешенки на промышленной основе, первую продукцию которого планируется получить в конце 2016 г. Примечательно, что этот проект стал детищем одного из бывших совладельцев крупной новосибирской IT-компании, который рискнул сделать ставку на экзотический для района аграрный бизнес [7]. Способствуют диверсификации экономики района и другие проекты, связанные с глубокой переработкой леса, получением пихтового масла, бутилированием качественной питьевой воды (в экспортном варианте) и фасовкой меда под брендом «салаирских продуктов», а также начавшееся зарыбление части водоемов и организация мест для спортивной рыбалки. Можно сказать, что «дирижистские» усилия руководства района в сочетании с предпринимательским креативом, направленным на создание и продвижение местных брендов, привели к началу формирования так называемых «инклюзивных» механизмов развития сельской территории.

\section{Болезни роста и перспективы местных брендов}

К неудачам развития экономики Маслянинского района можно отнести задержку с запуском нового кирпичного завода, оборудованного итальянской линией для производства высококачественных облицовочных материалов. В настоящее время готовы корпус для монтажа технологической линии и необходимые коммуникации, но итальянские партнеры сорвали поставку оборудования. Теперь в районе пытаются найти покупателя на возведенный производственный корпус, который бы смог наладить это производство. Другой сбой произошел с заводом по розливу питьевой воды: его собственники не справились с высокой конкуренцией на этом рынке и были вынуждены продать свой бизнес.

Но главные разочарования случились в основной отрасли местной экономики - в аграрном секторе. В 2016 г. корпорация «Хорс», специализирующаяся на производстве и переработке 
льна-долгунца, объявила себя банкротом. Принадлежащее ей сельхозпредприятие отказалось от проведения посевной кампании. Оставшихся с 2015 г. запасов сырья хватило для работы аффилированного с «Хорсом» льнозавода только на полгода. В итоге более 8000 га пашни, в которые было вложено немало средств, остались без обработки и заросли сорняками. Технологические линии на льнозаводе остановлены, люди лишились работы. Для района, «визитной карточкой» которого долгое время служило льноводство ${ }^{2}$, это было связано с немалыми экономическими и репутационными издержками.

Причин банкротства несколько. Во-первых, неблагополучное в природно-климатическом отношении трехлетие (2012-2014 гг.). Во-вторых, отсутствие действенных механизмов страхования подобных случаев оставило предприятия без требуемых компенсаций. В-третьих, ситуацию усугубила высокая кредитная нагрузка предприятий, вызванная необходимостью модернизации технической базы (закупки льноводческих комбайнов и другой сельскохозяйственной техники, а также оборудования для завода). Корпорации стало банально не хватать средств для обслуживания своих долгов, и ей пришлось объявить дефолт. В итоге был назначен конкурсный управляющий, а оформленные под залог займов земля, техника и оборудование перешли в собственность кредиторов.

Разорение льноводческого бизнеса обернулось утратой другой фирменной для района отрасли - козоводства, которым на свой страх и риск, помимо традиционного животноводства, начали заниматься 10 лет назад в одном из местных сельхозпредприятий. С 2009 г. произведенное здесь козье молоко стало сертифицироваться и перерабатываться на местном молочном заводе, а через несколько лет козьи йогурты и сыры из Маслянино стали поставляться в новосибирские торговые сети. Несмотря на удачное продвижение этого бизнеса, обустройство козьей фермы и рост дойного стада до 220 коз и 400 коров, предприятию хронически не хватало оборотных средств и ресурсов для переоснащения производственного комплекса. Имеющейся техники было

${ }^{2}$ В 2012-2013 гг. Новосибирская область занимала первое место среди субъектов РФ как по валовому сбору, так и по урожайности льна-долгунца. При этом основным производителем льна в области был Маслянинский район [8]. 
недостаточно для обработки с учетом всех агротехнических норм 10000 га пашни.

По поводу земли в 2013 г. было заключено соглашение между этим животноводческим хозяйством и корпорацией «Хорс». Дело в том, что присутствие в районе «Сибирской нивы», сумевшей аккумулировать к этому времени до $70 \%$ районной пашни и поглотить девять бывших колхозов и совхозов, усилило спрос на сельскохозяйственные земли. Предприятия «Хорса» нуждались в удвоении площади обрабатываемых земель, чтобы выйти на нужный объем производства сырья для льнозавода. Поэтому его менеджеры обратили внимание на автономное от «Сибирской нивы» животноводческое хозяйство. Предполагалось, что животноводы в кооперации со льноводами смогут получить недостающие им для модернизации средства, а налаженный семипольный севооборот обеспечит рост урожайности и получение высококачественной льняной соломы, позволит кардинально улучшить кормовую базу и повысит отдачу от животноводческой отрасли, а в потенциале позволит осуществить ввод в хозяйственный оборот всей неиспользуемой земли.

Вначале речь шла о раздельном ведении льноводческого и животноводческого хозяйств, но в итоге произошло их слияние. Однако альянс оказался недолговечным. Поглощенное льноводами хозяйство стало заложником финансовой ситуации, в которую попала корпорация. В конечном счете это привело к стремительной распродаже сельскохозяйственных животных и ликвидации производства.

Неудачи одного из крупных инвесторов, с которым в районе связывались большие надежды, свидетельствуют о том, что техническое обновление и диверсификация деятельности далеко не всегда приводят к планируемому результату. Крупные инвестиционные проекты создают новые риски, с которыми бывает не под силу справиться бизнесу даже в сотрудничестве с местной властью [9]. Важно отметить, что на федеральном и региональном уровне льноводы не пользовались тем уровнем поддержки, которую получали и получают от государства крупные производители молока, решая поставленную перед ними задачу по импортозамещению [10]. Можно сказать, что отсутствие у льноводческой отрасли в целом, а также у небольших животноводческих компаний страховых гарантий и возможностей софинансирования капитальных затрат, которые получала 
из регионального бюджета «Сибирская нива» в качестве инвестора стратегического для Новосибирской области проекта, стало для «Хорса» и его партнеров фатальным.

В настоящее время администрация района занята поиском новых инвесторов, которые бы смогли выкупить у кредиторов весь оставшийся после банкротства льноводов имущественный комплекс, снова заняться выращиванием льна и оживить простаивающие заводские цеха, которые без поставок местного сырья могут превратиться в груду металлолома. Чтобы возродить этот важный бренд, администрация района наложила мораторий на передачу освободившейся земли (из районного фонда перераспределения) другим сельхозпроизводителям, прежде всего «Сибирской ниве». Ведутся переговоры с конкурсным управляющим о приостановке распродажи имущества по частям, а также разьяснительные беседы с пострадавшими от банкротства местными жителями, потерявшими вместе с доходами от сдачи земельных паев в аренду и свои рабочие места.

\section{Поступь аграрного капитализма: цена побед}

В результате описанных выше пертурбаций монопольное положение в аграрном секторе Маслянинского района заняла «Сибирская нива», совершившая за прошедшее десятилетие огромный рывок в развитии индустриальных технологий производства молока. За это время компанией было построено два животноводческих комплекса беспривязного содержания животных на 4300 голов. Расположенные в них доильные залы типа «карусель» способны одновременно обслуживать на первом комплексе 36, на втором 72 коровы. Годовые надои молока выросли на предприятии за 10 лет в 2,5 раза: с 3575 кг на фуражную корову в 2006-2009 гг. до 8900 кг (согласно прогнозу конца 2016 г.). За этот период валовое производство молока на предприятии увеличилось почти в 12,5 раза - с 3 до 37,6 тыс. т в год. Достигнутые «Сибирской нивой» успехи позволили Маслянинскому району в 2016 г. наконец-то преодолеть «рекорд» советских времен. По прогнозам, производство молока в 2016 г. составит 41 тыс. т против 38,8 тыс. т в 1990 г. Кратный рост продуктивности молочного стада обеспечил превышение «советских» валовых показателей при сокращении поголовья всего дойного стада на 60\% (с 12,8 тыс. голов в 1990 г. до 5,2 тыс. голов в 2016 г.). 
Амбициозное руководство агрохолдинга не скрывает своих намерений по дальнейшей экспансии. В планах - удвоение молочного стада на уже построенных комплексах в течение ближайших 2-3 лет, в перспективе - строительство еще одного. Также планируются создание откормочной площадки на 10 тыс. голов молодняка, завершение строительства элеваторного комплекса с входящим в его состав комбикормовым заводом. Компания ориентируется на кормовую самообеспеченность - для этого она постоянно наращивает свой земельный клин, разнообразит севооборот новым ассортиментом многолетних трав и кормовых культур. Наряду с племенной работой большое внимание уделяется семеноводству, часть продукции растениеводства, в том числе семян, поставляется на рынок. Компания ориентирована на создание длинных цепочек добавленной стоимости и планирует дальнейшее развитие собственной перерабатывающей базы. Упомянутый завод «под стеклом» заменит действующий модульный цех по производству молочной продукции, перерабатывающий всего лишь чуть более $10 \%$ производимого молока.

Несколько лет назад «Сибирская нива» начала заниматься мясным животноводством. Впервые за Уралом здесь стали применять технологию круглогодичного беспривязного содержания крупного рогатого скота мясных пород. Даже в 40-градусные сибирские морозы животные располагаются под открытым небом. Перед тем как запустить в маслянинские леса тысячу голов абердин-ангусской породы, руководство компании вместе с главой района подробно ознакомились в Канаде с технологией, заметно сокращающей издержки на содержание скота, и приглашали к себе иностранных специалистов. Специалисты сразу оценили преимущества сибирской территории в сравнении с Северной Америкой. Для вольно пасущихся животных в Сибири гораздо больше доступных запасов воды, которую они могут употреблять даже зимой либо в виде чистейшего снега, либо из мелких речушек и ручейков, не замерзающих на перекатах. К тому же в сибирских лесах нет влажных арктических ветров, приводящих к образованию ледяной корки, которая травмирует животных. В администрации района рассчитывают на наращивание поголовья мясного скота до 25 тыс. голов и строительство мясоперерабатывающего завода. Таким образом, Маслянинский район может стать локацией для сибирского 
аналога агропромышленного холдинга «Мираторг», ведущего производителя и поставщика мяса на российском рынке.

Достигнутые результаты были бы невозможны без серьезных инвестиций. Как показал наш анализ, выполненный на основе данных финансовой отчетности, на протяжении всего периода существования «Сибирская нива» увеличивала свой кредитный портфель. При этом сумма привлекаемых ими долгосрочных кредитов и займов росла заметно быстрее выручки. Долгосрочные займы и кредиты компании с 2009-2013 гг. выросли в 3,7 раза (с 483 до 1800 млн руб.), перевалив в 2014 г. рубеж в 2 млрд руб. В то же время за этот период выручка в годовом измерении увеличилась в три раза (со 187 до 554 млн руб.). Таким образом, ликвидность предприятия поддерживалась за счет возрастающих объемов внешнего финансирования - банковских кредитов и государственной поддержки, что весьма важно для крупных животноводческих комплексов, требующих больших первоначальных вложений [11].

«Сибирская нива» с самого начала своей деятельности в Маслянинском районе опиралась на административный ресурс и пользовалась большой государственной поддержкой. В Новосибирской области она успешно вошла в областную программу развития животноводства, предусматривающую компенсацию до половины затрат на приобретение сельскохозяйственной техники, 20\% затрат на закупку скота, а также льготное кредитование оборотных средств. В середине 2000-х гг. проект строительства первого животноводческого комплекса получил региональное софинансирование. Финансовую поддержку наряду с другими крупными аграрными проектами, развиваемыми в Сибири, холдинг получал и в дальнейшем. В 2013 г. общая сумма государственной поддержки предприятия составила 178,7 млн руб. [12] и в 8,8 раза превысила прибыль компании. Очевидно, что при отсутствии помощи возможность рентабельного ведения бизнеса такого масштаба была бы под большим вопросом.

Пример «Сибирской нивы» очень показателен в плане сложившихся приоритетов в распределении государственной поддержки. Отсутствие сопоставимой помощи для льноводов обернулось их разорением. Также в «падчерицах» у государства и районных властей находятся два небольших сельхозпредприятия, сохранивших самостоятельность, и девять фермерских хозяйств, которые уже 2 ЭКО. - 2017. - №1 
не рассчитывают на значительную внешнюю поддержку. Усиление положения «Сибирской нивы» и ее настрой на продолжение земельной экспансии серьезно повлияли на поведение игроков из «младшей профессиональной лиги». Более сильные фермеры были вынуждены выкупать долевые земли, предлагая их владельцем более высокие, чем у агрохолдинга, цены, и даже арендовать земли соседнего района, вынужденно вкладываясь в рекультивацию долгое время не обрабатываемых полей.

Произошедшая аграрная «реиндустриализация» кардинально поменяла систему сельской занятости. По сравнению с 1990-ми гг. количество сельскохозяйственных работников в Маслянинском районе сократилось в пять раз, большая часть из которых (около 700 из 1000 человек) работают в подразделениях «Сибирской нивы». Хотя уровень заработных плат в компании заметно повысился, но труд стал более напряженным и ответственным. В связи с этим рабочие места стали недоступны для тех, кто не справляется с высокой интенсивностью конвейерного производства в молочном комплексе или многочасовой нагрузкой при работе на сельскохозяйственной технике на участках, рассредоточенных по территории района. Кардинально сменился образ жизни сельских жителей. Они стали более мобильны и менее привязаны к своим подворьям. Прежняя прикрепленность рабочих мест в колхозах и совхозах к сельским поселениям ушла в прошлое. Теперь, чтобы попасть на свое рабочее место, занятые в «Сибирской ниве», тратят время, сопоставимое с крупным городом.

\section{Инициатива на местах: егорьевские россыпи}

По нашим наблюдениям, сельское развитие не ограничивается инициативами районной администрации. Показательным в этом отношении является пример села Егорьевское, в котором сложилась своеобразная мини-модель моноресурсного региона. Большая часть трудоспособных мужчин традиционно занята в золотодобыче, которая ведется в этих местах с 1830 г. Женщины столь же традиционно заняты в социальной сфере и в домашнем хозяйстве. Достойные по сельским меркам доходы местных жителей парадоксально сочетаются с более чем скромными возможностями бюджета муниципального образования. Четыре артели на участках, расположенных в окрестностях села, ежегодно добывают золота на сумму в несколько сотен миллионов 
рублей, а в местный бюджет поступают сущие крохи - $10 \%$ от НДФЛ. Основным источником доходов являются трансферты из районного бюджета.

В этой непростой ситуации глава местного сельсовета, коренной житель по рождению и местный патриот по жизни, демонстрирует незаурядные навыки организатора жизнедеятельности Егорьевска и окрестных поселений: обустраивает село, улучшает его инфраструктуру, увеличивает места приложения работы, привлекает инвесторов. В его управленческом арсенале присутствуют разнообразные формальные и неформальные методы взаимодействия с местными работодателями. Прежде всего, он настаивает на местной регистрации предприятий, работающих на территории сельсовета.

Действия главы сельской администрации направлены на то, чтобы закрепить и легализовать (зарегистрировать) права собственности на имущество, расположенное на территории муниципального поселения. Цель - создать диверсифицированный имущественный комплекс и получать в местный бюджет дополнительные доходы от сдачи его в аренду. Речь идет о земле, дворах, постройках, оставшихся после банкротства сельхозпредприятия в селе Суенга, которые длительное время не имели оформленной регистрации. Немалые усилия он приложил для изменения статуса земли, чтобы ее обустроить и привлечь инвесторов для развития местного туризма.

Еще один местный проект можно назвать рекреационным - он предполагает создание каскада озер для разведения форели и организации рыбалки на месте водоемов, оставшихся на выработанных старателями участках. Его реализация «убивает двух зайцев». С одной стороны, золотодобытчики выполняют предусмотренные законом обязательства по рекультивации земли, а с другой - на месте образуется еще один небольшой бизнес, повышающий туристическую привлекательность района. Этот проект выставляется «на продажу» - заниматься разведением рыбы и приглашать туристов для спортивной рыбалки будут привлеченные заранее созданной инфраструктурой предприниматели. Еще один проект - создание туристических маршрутов к старателям, чтобы желающие могли попробовать себя в роли золотоискателей.

В продвижении своих инициатив глава поселения полагается на индивидуальный подход и неформальное конструирование 
«человеческих отношений». Он сочетает силу убеждения и имеющиеся у него властные рычаги для подключения местных предпринимателей к решению самых важных для жителей села проблем. Хорошие отношения с местным предпринимательским сообществом и с властями разных уровней позволяют смягчить бюджетные ограничения, снимают пробелы и нестыковки формальных институтов сельского самоуправления и в конечном счете способствуют практическому воплощению местных инициатив. Мизерность местного бюджета отчасти компенсируется недюжинной активностью руководства по привлечению дополнительных денег за счет включения в государственные и муниципальные программы, участия в конкурсах на получение грантов, активного лоббирования интересов поселения на районном и областном уровнях.

В планах главы поселения - организация дома-музея об истории села, об истории золотодобычи в этих местах. Не забыты и трагические моменты истории Гражданской войны. Создается и мостик в будущее: в селе разбит «именной парк», в котором любой желающий, местный или приезжий, может оставить о себе память, посадив дерево.

\section{$\star \star \star$}

Не претендуя на выводы о ближайших и отдаленных перспективах развития района, авторы хотели бы обобщить типичные проблемы, с которыми сталкиваются инициативные и нацеленные на «сельскую реиндустриализацию» руководители районного масштаба.

Местное самоуправление обеспечивает устойчивость властной пирамиды, но при этом в последние годы полномочия муниципалитетов все в меньшей степени обеспечиваются их собственными финансовыми ресурсами, они все более зависят от трансфертов, поступающих сверху. Это порождает массу проблем, связанных с реальными полномочиями и ответственностью местных властей.

Следует констатировать, что легитимные и работоспособные механизмы пресловутого «государственно-частного партнерства» - взаимодействия органов власти с частным бизнесом в процессах реализации как программ сельского развития, так и отдельных проектов, еще не отработаны. Полномочия и степень 
ответственности участников в условиях софинансирования и концессий не всегда четко определены, а смешение государственных и частных денег в одних проектах чревато экономическими потерями для государства и правовыми рисками как для местных администраций, так и предпринимателей.

В таких условиях реальными инициаторами сельского развития могут быть руководители муниципальных образований, представители крупного бизнеса, другие предприниматели, пытающиеся создать и продвинуть на рынок местные бренды. Участие крупного бизнеса может сулить быстрые и очевидные успехи на ниве сельской реиндустриализации, но вместе с тем порождает опасность превращения сельских районов в своеобразные монотерритории, процветание или упадок которых критически зависят от положения дел в «районообразующей» компании (например, в агрохолдинге или в сырьевой корпорации). В этом случае районы в полной мере принимают на себя риски крупного бизнеса, а монополизация производства может стать непреодолимым барьером для дальнейшего экономического роста.

Главную проблему для сельского развития представляет увеличивающийся во времени разрыв между экономическими результатами территории и остающимися в ее распоряжении налоговыми доходами. Чем «ближе к земле», тем меньше у местных властей остается возможностей для самофинансирования собственных социальных и экономических инициатив. В нашем случае это обстоятельство отчасти демпфируется активностью районной администрации, умеющей получить деньги «сверху» на привлекательных условиях, а также умелым использованием местной синергии, которое мы наблюдали в селе Егорьевское. Однако следует понимать, что такое положение дел медленно, но верно подрывает факторы «инклюзивного» развития, постепенно превращая территории из субъектов в объекты управления, а местные администрации - в простых распорядителей субсидий и дотаций из бюджетов верхних уровней.

\section{Литература}

1. Ярманов В. В. Рецепты «маслянинского чуда» // ЭКО. - 2013. - № 5. C. $48-54$.

2. Кулешов В.В., Крюков В.А. Реиндустриализация Новосибирской области - учитывать общее, развивать особенное // ЭКО. - 2015. - № 10. C. 5-29. 
3. Селиверстов В.Е. Программа реиндустриализации экономики Новосибирской области: основные итоги разработки // Регион: экономика и социология. - 2016. - № 1. - С. 108-134.

4. Комплексная программа социально-экономического развития Маслянинского района на период 2008-2022 гг. URL: http://www.smo-nso.ru/ attachments/052_КПСЭР\%20Маслянинского\%20района.doc

5. «Салаир Олимпик» приготовят для привлечения федерального финансирования. URL: http://maslyanino.org.ru/novosti/zhizn-poselka/-salairolimpik-prigotovjat-dlja-privlec.html

6. Маслянинский мрамор предлагают иностранцам. URL: http:// maslyanino.org.ru/novosti/zhizn-poselka/untitled.html

7. Экс-глава IT-компании нашел грибное место. URL: http://maslyanino. org.ru/novosti/zhizn-poselka/yeks-glava-it-kompanii-nashel-gribnoe-me.html

8. Папело В. Н., Ковтун Б. А., Гааг А. В., Агапов Ю. В., Самохвалова А.А. Кластерная модель развития льняного подкомплекса России // Вестник НГАУ. - 2016. - № 1 (38). - С.175-180.

9. Долженков В.Н. Новый механизм господдержки в агростраховании не прошел испытание засухой // ЭКО. - 2013. - № 5. - С. 55-67.

10. Барсукова С. Ю. Молочные реки России // ЭКО. - 2016. - № 6. C. 5-17.

11. Фадеева О. «Дело было в Пенькове»: как агрохолдинги завоевывают сельские районы Сибири // Крестьяноведение: Теория. История. Современность. Ученые записки. Вып. 10; под ред. А. М. Никулина, М. Г. Пугачевой, Т. Шанина. - М.: Издательский дом «Дело» РАНХиГС, 2015. - С. 197-233.

12. Господдержка в НСО: «субъективный характер и признаки коррупциогенности» // Председатель. - 2014. - № 35.

\section{«ЭКО»-инФорм«}

\section{Маслянинский льнозавод выставят на торги}

Крупнейшее в Новосибирской области предприятие по переработке льна сегодня банкрот. Производственные линии остановлены. Бывшие сотрудники завода находятся в поисках работы.

Н. Носкова, бывшая сотрудница льнозавода: «Завод сейчас готовят к продаже, ищут новых инвесторов. Здесь производили утеплители из льна, который выращивали на маслянинских полях. Еще весной у ворот стояли грузовики в очереди за продукцией. В цехах завода импортное оборудование. Обновили несколько лет назад. Владельцы брали кредиты, но не смогли рассчитаться. В этом году не было посевной. Без сырья производство остановили... В долгах многие. Их сократили еще в начале лета. Должны были выплатить пособия. Но у предприятия денег нет.

Маслянинский лен - это бренд. Визитная карточка района. Его выращивали здесь более 200 лет... Есть ли надежда, что производство возобновят, или это крах отрасли?».

Источник: Вести - Новосибирск. URL: http://www.nsktv.ru/ 